\title{
Rentabilidade da Produção de Acerola Orgânica Sob Condição Determinística e de Risco: estudo do distrito de irrigação Tabuleiro Litorâneo do Piauí ${ }^{1}$
}

\author{
Élica de Aguiar Martins², Robério Telmo Campos³, \\ Kilmer Coelho Campos ${ }^{4}$ e Cleycianne de Souza Almeida ${ }^{5}$
}

Resumo: No Nordeste brasileiro, as alternativas de produção que se apresentam como economicamente viáveis são escassas e a produção de acerola orgânica pode ser situada entre aquelas que proporcionam aumento de renda e fixam as famílias no campo. Ante o exposto, objetiva-se avaliar a viabilidade da produção de acerola orgânica sob condição determinística e de risco no Distrito de Irrigação Tabuleiro Litorâneo do Piauí. Para tanto, foram utilizados dados primários referentes a uma amostra de 23 produtores em 2011. Como método de análise foram utilizadas medidas de resultado econômico para a avaliação determinística e o método simulação de Monte Carlo para a análise de risco. Para a avaliação determinística, constatou-se que dez produtores da amostra apresentaram inviabilidade econômica, com os demais apresentando rentabilidades aceitáveis. $\mathrm{Na}$ análise de risco obteve-se idêntico resultado, pois os produtores que não seguem as recomendações técnicas apresentaram-se inviáveis economicamente e com alto risco, enquanto que os mais tecnificados mostraram-se com alta rentabilidade e baixo risco. Sugerem-se políticas públicas tais como a oferta de cursos de capacitação e treinamento em produção de acerola orgânica, em gestão e comercialização agrícola e, em complementação, propiciar assistência técnica individualizada para auxiliar os produtores na correta utilização dos insumos.

Palavras-chaves: Medidas de resultado econômico; Simulação de Monte Carlo; Distrito de irrigação Tabuleiro Litorâneo; Piauí.

Abstract: In the Northeastern region of Brazil, production alternatives that are economically feasible are scarce and the organic acerola production can be set among those

1. Data de submissão: 21 de novembro de 2014. Data de aceite: 11 de novembro de 2015.

2. Universidade Federal do Piauí (UFPI). Parnaíba, Piauí, Brasil. E-mail: elicamartins@hotmail.com

3. Universidade Federal do Ceará (UFC). Fortaleza, Ceará, Brasil. E-mail: roberio@ufc.br

4. Universidade Federal do Ceará (UFC). Fortaleza, Ceará, Brasil. E-mail: kilmer@ufc.br

5. Universidade Federal do Ceará (UFC).Sobral, Ceará, Brasil. E-mail: cleyalmeida@gmail.com 
which increases income and keep the families in the rural areas. Therefore, this study aims to assess the feasibility of the organic acerola production under deterministic and risk conditions in the Irrigation District of Tabuleiro Litorâneo of Piaui State, Brazil. To this end, we used primary data gathered from a sample of 23 producers in 2011. As methods of analysis, we applied measurements of economic outcomes for the deterministic assessments and the Monte Carlo simulation method for risk analysis. The deterministic evaluation showed that ten producers from the sample were economically infeasible while the other had acceptable profitability. For risk analysis, we obtained similar results, noting that producers who had developed the activity without following technical recommendations were impractical and faced higher risk, whereas those who are more technified have higher profitability and lower risk. We suggest carrying out public policies such as the provision of training programs in organic acerola production and agricultural management and marketing, in addition to individualized technical assistance to support producers in the right use of inputs.

Key-words: Economic outcome measures; Monte Carlo simulation; Coastal Irrigation District Board; Piauí.

\section{Introdução}

A agricultura orgânica tornou-se recorrente na pauta de produção de vários países, demonstrando, no curso dos últimos anos, elevadas taxas de crescimento. Isto fez com que não só Ásia, América do Norte e Europa ampliassem seus segmentos de produção e consumo, mas também que vários outros países da Oceania e da América Latina evoluíssem nesta direção, em busca de oportunidades de mercado (WILLER e YUSSEFI, 2001).

Segundo estudos do Instituto Aqualung, o Brasil ocupa a $34^{\text {a }}$ posição no ranque dos países exportadores de produtos orgânicos, sendo que, na última década, foi identificado um crescimento de $50 \%$ das vendas por ano. Calcula-se que foram cultivados perto de 100 mil hectares em cerca de 4.500 unidades de produção orgânicas em todo o País. A maior parte da produção brasileira (cerca de $70 \%$ ) está nos estados do Paraná, São Paulo, Rio Grande do Sul, Minas Gerais e Espírito Santo. Apesar da tendência de crescimento, o Brasil ainda perde para a vizinha Argentina em termos de área certificada para o cultivo de orgânicos na América do Sul.

Os retornos sobre os investimentos em culturas orgânicas dependem de fatores internos à produção agrícola, como o nível tecnológico, pois, apesar de os produtores terem um padrão de tecnologia a ser seguido, muitos não a utilizam adequadamente, fazendo com que alguns atinjam boa produção por hectare, enquanto outros exibem reduzidas produtividades.

A capacidade gerencial do produtor também é vista como outro problema, pois muitos não têm o treinamento necessário para permitir melhor condução do negócio, não conseguindo produzir em escala eficiente. A disponibilidade de recursos é outro grande entrave para os produtores investirem mais e melhor em sua produção, pois os bancos dificultam muito a oferta de crédito para os pequenos produtores e, quando disponibilizados, os juros são relativamente altos, fazendo com que muitos deles não consigam ter capacidade de pagamento necessária para saldar as dívidas, agravando ainda mais a situação.

A dificuldade de geração de emprego e renda no campo é também um grave problema enfrentado pela população nordestina, e a produção de acerola orgânica irrigada surge como opção para reduzir esse problema.

Especificamente para o estado do Piauí, a produção de produtos orgânicos começou a tomar proporções de 2001 a 2003. Naquele momento, a produção de acerola orgânica passou a ser atividade alternativa e os agricultores foram encorajados por meio de incentivos propiciados pelo 
Banco do Nordeste e de novas tecnologias difundidas pela Embrapa Meio-Norte e universidades, objetivando dar início à produção de frutíferas orgânicas no estado.

O Distrito Irrigado Tabuleiros Litorâneos do Piauí (Ditalpi), localizado na região norte desse estado, produziu, em 2008, a média de 56 toneladas/hectare/ano de acerola, segundo informações da Cooperativa dos Produtores Orgânicos dos Tabuleiros Litorâneos do Piauí - Biofruta. Essa elevada produtividade alcançada no Perímetro o fez detentor de maior produtividade de acerola no Brasil, superando o Município de Petrolina, referência internacional na produção dessa fruta, produzindo $20 \mathrm{t} / \mathrm{ha}$ /ano.

Os produtores estão organizados em uma cooperativa denominada Biofruta que organiza, negocia e vende os produtos. A maior parte da produção de acerola orgânica do Ditalpi é vendida para a multinacional estadunidense Nutrilite, que tem sede em Ubajara, no Ceará.

Ante o exposto e considerando a importância econômica, ambiental, cultural e social do cultivo de acerola orgânica no Distrito de Irrigação Tabuleiro Litorâneo do Piauí (Ditalpi), faz-se a seguinte indagação: será que os produtores de acerola orgânica realizam uma exploração rentável, considerando todos os riscos inerentes a sua produção?

Em razão da alta produtividade obtida, pressupõe-se que a produção de acerola orgânica desenvolvida pelos produtores associados à Cooperativa Biofruta, no Ditalpi, denota rentabilidade aceitável e baixo risco.

Portanto, este ensaio examinou a produção de acerola, por meio de dados de custos de produção e de receitas dos produtores que fazem a exploração sob o sistema de plantio orgânico. Desta forma, especificamente, os objetivos deste estudo são investigar a viabilidade econômica sob dois enfoques, determinístico e de risco, para comprovar se a atividade expressa nível de rentabilidade suficiente para cobrir os custos dos insumos e remunerar os fatores de produção (terra, capital e trabalho), a fim de garantir a continuidade do produtor na referida exploração.

\section{Análise de risco}

Um dos métodos utilizados na análise de risco é o de análise de sensibilidade. Esta metodologia permite verificar o grau de mudança em um indicador, fazendo-se alteração em uma variável. De acordo com Pareja (2009), a análise de sensibilidade permite medir a mudança de um resultado (ou indicador) por meio da troca de cada uma das variáveis, tanto em termos relativos como absolutos.

As variáveis que mais alterarem o indicador com a mudança são denominadas de críticas. Verificadas as variáveis críticas, ou seja, aquelas que mais alteram o resultado, estas devem ser utilizadas em um modelo de simulação, a fim de que se dediquem esforços ao que for realmente importante.

Ainda de acordo com Pareja (2009), a maneira mais simples de se fazer a análise de sensibilidade é examinar as mudanças de um resultado, ao se fazer uma mudança de $1 \%$ em cada variável, uma de cada vez (isto significa que, feita a mudança de uma variável, se deve retornar ao modelo com seus dados originais para fazer novamente a mudança de $1 \%$ em outra variável).

A análise de sensibilidade identifica as variáveis que determinam o sucesso do projeto, mas não mede o risco associado a essas variáveis. É evidente que qualquer estudo de viabilidade econômica tem inerente sempre um fator de incerteza, e a análise de sensibilidade não foge a esta regra. Por isso, deve-se fazer uma análise de risco após realizar a de sensibilidade.

Ao se reconhecer o fato de que, no mundo real, as variáveis que intervêm no sistema econômico possuem componente aleatório, os modelos deterministas comumente utilizados nas tomadas de decisões passaram a ser intensivamente questionados, dando espaço para que modelos mais realísticos, considerando risco ou incerteza, fossem desenvolvidos e aplicados.

Conviver com o risco é um fato comum em qualquer atividade econômica, principalmente em se tratando de projetos econômicos rurais, pois fatores incontroláveis influem negativamente na rentabilidade do investimento, como sazonalidade, pragas, chuvas excessivas e secas. 
012 - Rentabilidade da Produção de Acerola Orgânica Sob Condição Determinística e de Risco: estudo do distrito de irrigação Tabuleiro Litorâneo do Piauí

Dentre os métodos utilizados na análise de risco, a simulação Monte Carlo, segundo Noronha (1988, p. 135), "é o procedimento mais simples do ponto de vista prático, pois nem estimativas muito otimistas nem muito pessimistas satisfazem completamente a tomada de decisões", sendo, portanto, "bastante utilizado em avaliações desta natureza, à medida que fornece uma ideia das probabilidades de ocorrência de situações adversas, bem como suas consequências sobre os resultados do empreendimento".

O método de Monte Carlo (MMC) fornece soluções aproximadas a uma variedade de problemas matemáticos mediante testes (experimentos) de amostragens estatísticas em computador. O método aplica-se extraordinariamente bem tanto a problemas absolutamente não probabilísticos como àqueles com estrutura inerentemente probabilística. Somente isso não daria ao método de Monte Carlo vantagem sobre outros métodos de aproximação. Porém, dentre todos os métodos numéricos que contam com n-pontos de avaliação num espaço $m$-dimensional para produzir soluções aproximadas, o MMC tem o erro absoluto de suas estimativas diminuindo a $\mathrm{n}^{-1 / 2}$, enquanto todos os outros têm erro absoluto de estimativa decrescendo a $\mathrm{n}^{-1 / \mathrm{m}}$ no máximo. Esta propriedade confere ao MMC considerável vantagem na eficiência computacional quando $m$, o tamanho do problema, aumenta (FISHMAN, 1995).

O modelo de simulação de Monte Carlo, segundo Pouliquen (1970), é conveniente, também, por não envolver metodologia sofisticada e ser facilmente aplicado por meio de simulação em computadores; ser confiável, porque o empresário toma decisões se baseando numa distribuição de probabilidade cumulativa e não em única informação, e não exige maiores gastos em amplas pesquisas de campo.

A simulação de Monte Carlo é uma metodologia adotada com bastante frequência no campo da análise de risco, seja para examinar a variabilidade das características estudadas, sob distintas realidades, seja para quantificar o risco de certos eventos (STUDART, 2000).

\section{Metodologia}

\subsection{Caracterização da área de estudo}

A escolha da área de estudo foi motivada pelo fato de a produção de acerola estar localizada num perímetro irrigado e significar uma das maiores produtividades de acerola orgânica do Brasil. O Perímetro Irrigado Tabuleiros Litorâneos do Piauí, sub-rogado ao DNOCS, está localizado entre os municípios de Parnaíba e Bom Princípio, na região litorânea do Piauí.

\subsection{Natureza e fontes de dados}

Neste estudo, foram usados tanto dados primários como secundários. Os indicadores primários, relacionados ao período de 2011, foram obtidos por meio de entrevistas, visitas e questionários aplicados junto aos produtores da Cooperativa Biofruta. Os de teor secundário foram extraídos de pesquisas bibliográficas em livros, internet, teses e dissertações, para dar embasamento teórico sobre o tema proposto acerca da análise de risco.

\subsection{População e amostra}

Existem estudos em que seria quase impossível examinar todos os elementos da população. Quando a população de um estudo for considerada infinita, é aconselhável o uso de amostra. Quando é muito pequena $(<50)$, a característica é de fácil mensuração e há tem necessidade de alta precisão.

Foi utilizada neste experimento uma amostragem não probabilística, pois a população analisada é muito pequena, contendo apenas 23 produtores de acerola orgânica do Perímetro Irrigado Tabuleiros Litorâneos do Piauí, associados à cooperativa Biofruta. Todos os produtores expressam mais de dois anos de experiência em irrigação de produtos orgânicos, recebem assistência técnica periódica de técnico da cooperativa, utilizam a microaspersão como sistema de irrigação e produzem em uma área irrigada de até dez hectares. 


\subsection{Método de análise}

\subsubsection{Perfil dos produtores de acerola orgânica}

A análise e a interpretação dos dados foram efetuadas de acordo com o método descritivo e com a técnica de análise tabular, com a utilização de frequência absoluta e relativa das variáveis selecionadas. Os principais aspectos e as variáveis analisadas para definir a configuração e caracterizar a exploração estão expressos na sequência.

1. Identificação do produtor: idade, grau de instrução, experiência em irrigação, experiência em produção orgânica irrigada, local de residência, faixa etária dos membros da família, membros familiares que trabalham na propriedade, quem recebe assistência técnica e com que frequência, capacitação e treinamento, grau de satisfação e benefícios de produzir acerola orgânica.

2. Aspectos agroeconômicos da propriedade: condição legal da propriedade, área da propriedade, decisão de produção, tipos de sistemas de irrigação e elaboração de projeto inicial.

\subsubsection{Mensuração da Renda Bruta e dos custos e cálculo dos indicadores}

Para Buarque (1989), se a rentabilidade de um projeto determina a sua viabilidade, o cálculo das receitas e dos custos é o ponto culminante do estudo do projeto. A rentabilidade econômica dos produtores foi analisada, utilizando-se as seguintes medidas de resultado econômico definidas por Campos (2003).

a) Renda Bruta:

$$
R B=\sum_{i=1}^{n}(P i Q i)
$$

em que:

$R B$ = renda bruta da produção (no caso, a produção de acerola em 2011);
$P i=$ preço ao produtor do produto $i,(i$ $=1,2, n)$; $Q i=$ quantidade produzida do produto $i$.

b) Custo Operacional Efetivo (COE) ou Custo Variável Total (CVT): é o somatório das despesas com insumos e mão de obra temporária, ou seja, dispêndio efetivo (desembolso) realizado pelo produtor para produzir acerola:

$\mathrm{COE}=\sum_{h=1}^{m}(P h Q h)+\sum_{j=1}^{r} P j Q j$

em que:

$P h=$ preço da diária ou do serviço contratado temporário $h,(h=1,2, m)$;

$Q h=$ quantidade de mão de obra ou do serviço contratado temporário $h$;

$P j=$ preço do insumo $j,(j=1,2, r)$;

$Q j=$ quantidade do insumo $j$.

c) Custo Operacional Total (COT): é o somatório do COE e dos outros custos operacionais não desembolsáveis (depreciação, encargos diretos, seguro, encargos financeiros e outras despesas). Especificamente, para este estudo, foram considerados os seguintes itens:

$C O T=C O E+D+M O P$

em que:

$D=$ depreciação de máquinas e equipamentos e benfeitorias;

$M O P=$ mão de obra permanente.

d) Custo Total (CT): é o somatório do COT mais os juros ou a remuneração do capital $(R C)$ e a remuneração da terra (RT), pertencente ou não à empresa, e a remuneração do empresário (RE).

$C T=C O T+J+R E$

em que:

$C T=$ custo total;

$\mathrm{COT}=$ custo operacional total;

$J=$ juros sobre terra e capital empatados;

$R E=$ remuneração do empresário. 
A determinação dos indicadores financeiros para a análise de viabilidade econômica da produção de acerola orgânica na cooperativa Biofruta foi baseada nas medidas defendidas por Martin et al. (1998) e Hoffmann et al. (1992).

a) Margem Bruta (MB): indica o que sobra de dinheiro, no curto prazo, para remunerar os custos fixos. A margem bruta positiva significa que a exploração está se remunerando e sobrevivendo no curto prazo. A margem bruta negativa significa que atividade está antieconômica naquele período. Este indicador é intuitivamente muito bem compreendido e operacionalizado pelos produtores.

A margem bruta absoluta ou em valores monetários é calculada subtraindo-se da renda bruta (RB) o custo operacional efetivo (COE). Assim, tem-se:

$M B=R B-C O E$

b) Margem Líquida (ML): mede a lucratividade da atividade no curto prazo, mostrando as condições financeiras e operacionais da atividade agrícola. Essa margem indica a sobra de caixa para cobrir os demais custos fixos e o risco, não computados nesta análise. Se a ML for negativa, o produtor pode não abandonar a exploração, mas poderá corresponder a um empobrecimento ou redução de seu capital.

A Margem Líquida (ML) absoluta ou em valores monetários, chamada também de Receita Líquida Operacional, é o resultado da diferença da Renda Bruta (RB) e o Custo Operacional Total (COT), ou seja:

$M L=R B-C O T$

c) Receita Líquida (RL): é a diferença entre a Renda Bruta e o Custo Total, constitui-se em resíduo que servirá para remunerar o empresário. Quando seu resultado é positivo, pode-se assinalar que a atividade se encontra estável e com possibilidade de expansão. A receita líquida nula significa que a atividade está em ponto de equilíbrio e em condições de refazer no longo prazo seu capital fixo. Em caso de Receita Líquida Negativa e Margem Bruta Positiva, pode-se concluir que o empresário pode produzir por determinado período, embora com um problema crescente de descapitalização.

Este indicador é definido como o cálculo da diferença entre a Receita Bruta (RB) e o Custo Total (CT) sendo obtida matematicamente por:

$R L=R B-C T$

Neste estudo, os Custos Totais (CT) definem-se pela expressão:

$C T=C O T+J+R E$

d) Taxa de Remuneração do Capital (TRC): é uma medida importante para se analisar a eficiência no uso do capital. Esta medida é indicada, inclusive, para se avaliar a eficiência da utilização do capital em propriedades de tamanhos diferentes, por se tratar de uma medida relativa. É obtida por meio da divisão entre a Renda do Capital (RC) e o Capital Médio Empatado (C), multiplicando-se o resultado por 100. Assim, matematicamente, tem-se:

$T R C=(R C / C) \times 100$

A Renda do Capital (RC), neste estudo, é estimada por meio da diferença entre a Receita Líquida (RL) e a Remuneração Pré-Atribuída à Terra (RT), sendo obtida matematicamente por:

$R C=R L-R T$

e) Ponto de Equilíbrio de Preço (PEP), ou custo médio: mostra qual o preço mínimo que o produtor deve vender seu produto para que ele consiga pagar seus custos de produção.

$P E P=\frac{C T}{Q}$ 
em que:

PEP = Ponto de Equilíbrio de Preço, ou

Custo Médio;

CT = Custo Total de Produção de Acerola;

$Q=$ Quantidade Produzida de Acerola.

f) Ponto de Nivelamento de Rendimento

(PNR): mostra de quanto deve ser a produção mínima, dado o preço de venda do produto, para que os custos sejam cobertos (KAY, 1986).

$P N R=\frac{C T}{P}$

em que:

PNR = Ponto de Nivelamento de

Rendimento;

CT = Custo Total;

$P=$ Preço Pago ao Produtor por $\mathrm{kg}$ de acerola vendido.

\subsubsection{Análise probabilística pelo método Monte Carlo}

Para avaliar o risco envolvido nos diversos sistemas, foi empregada a técnica da simulação de Monte Carlo. O princípio básico dessa técnica reside no fato de que a frequência relativa de ocorrência do acontecimento de certo fenômeno tende a se aproximar da probabilidade de ocorrência desse mesmo fenômeno, quando a experiência é repetida várias vezes, assumindo valores aleatórios dentro dos limites estabelecidos (HERTZ, 1964).

Considerando-se que os produtores associados da cooperativa Biofruta se encontram em plena atividade e sujeitos a fatores de risco, procurou-se efetuar a análise sob condições de risco. Para a sua aplicação, deve-se lançar mão das suas respectivas distribuições cumulativas de probabilidades. De acordo com Campos (1991), matematicamente, o método se comporta como segue:

$$
I_{\mathrm{dj}}=g\left(P_{\mathrm{di}}, W_{\mathrm{dz}}, \mathrm{PR}_{\mathrm{di}}, S_{\mathrm{dz}} ; V\right)
$$

em que:

$I_{\mathrm{dj}}=$ distribuiç̧ão cumulativa de probabilidade do j-ésimo indicador;
$P_{\mathrm{di}}=$ distribuição cumulativa de probabilidade do preço real do $i$-ésimo quilo de acerola produzida; $W_{\mathrm{dz}}=$ distribuição cumulativa de probabilidade do preço real do z-ésimo insumo utilizado na produção da acerola orgânica;

$P R_{\mathrm{di}}=$ distribuição cumulativa de probabilidade da produtividade ou produção do $i$-ésimo quilo de acerola;

$S_{\mathrm{dz}}=$ distribuição cumulativa de probabilidade da quantidade do z-ésimo insumo utilizado na produção de acerola;

$V=$ vetor de parâmetros ou variáveis deterministas da função.

Por meio da utilização do programa Excel, propõe-se uma distribuição de probabilidade para cada uma das variáveis, que pode ser a distribuição triangular, normal, quadrática, retangular, spike (constante) ou qualquer outra. Mediante a geração de números aleatórios, valores são obtidos para essas variáveis e, consequentemente, vários indicadores de resultado econômico podem ser calculados. Pela repetição desse procedimento, em um número significativo de vezes, gera-se a distribuição de frequências do indicador de análise, que permite aferir a probabilidade de sucesso ou insucesso do empreendimento (PONCIANO et al., 2004).

A seguir, descrevem-se de maneira detalhada as quatro etapas utilizadas neste estudo e que compõem o Método Monte Carlo.

\section{Identificação das Distribuições de Proba-} bilidade: pelo fato de ser grande o número de variáveis a considerar, tornou-se tarefa ambiciosa, ou mesmo impraticável, determinar a distribuição de probabilidade de todo o conjunto. Assim, foram consideradas como aleatórias apenas aquelas de maior importância (doravante denominada de relevantes) e as demais, como determinísticas, ou seja, de valor constante. Neste estudo, inicialmente, se fez uso da análise de sensibilidade para determinação e separação das referidas variáveis (POULIQUEN, 1970).

Definidas as variáveis consideradas relevantes, Santos (1996) recomenda como 
próximo passo a determinação do tipo de distribuição que elas irão assumir na análise, podendo ser de tipos diversos, sendo as mais importantes - normal, beta, uniforme, trapezoidal, discreta, triangular e retangular.

A distribuição de probabilidade adotada para todas as variáveis aleatórias é a triangular, pois, segundo Poliquen (1970), esta distribuição se aplica bem quando existe baixo grau de informações a respeito das variáveis, isso porque a distribuição é definida pelo seu nível médio ou pela moda (md), extremada por um nível Mínimo (Mn) e outro Máximo (Mx), de modo que:

$\operatorname{Prob}(M n \leq X \leq M x)=100 \%$

2. Simulação de Valores Aleatórios: nesta etapa, foram simulados ou gerados, mediante a utilização de computador, representados pelos valores médios, mínimos e máximos, os valores aleatórios para cada variável eleita como relevante na etapa anterior, com base nas distribuições de probabilidade identificadas. Nesta etapa, bem como nas seguintes, foi utilizado o software 'Aleaxpri', um sistema para simulação e análise de projetos envolvendo risco, desenvolvido por Azevedo Filho (1988).

3. Cálculo dos Indicadores: depois de selecionado um valor para cada variável aleatória (valor médio, mínimo e máximo), foram calculados os indicadores de rentabilidade, objeto de análise no estudo sob relatório.

As etapas (2) e (3) foram repetidas tantas vezes quantas forem estipuladas as simulações das variáveis, de modo que, para cada conjunto de dados simulados das variáveis, tem-se uma estimativa para cada indicador em análise.

4. Distribuição Cumulativa de Probabilidade: ao repetir as etapas (2) e (3), gerou-se igual número de valores para os indica- dores de rentabilidade, com origem nos quais foi possível estimar a distribuição de frequência com os dados agrupados em intervalos de classe e, consequentemente, obter a distribuição de frequência na forma acumulada. Assim, foram obtidas as distribuições acumuladas de probabilidade que fornecem indicações sobre o grau de risco que o tomador de decisão assume em relação à atividade. De acordo com Noronha (1988), sabe-se que o risco continuará existindo, entretanto, se dispõe de informação mais completa sobre a probabilidade de ocorrência.

\section{Resultados e discussão}

\subsection{Perfil dos produtores de acerola da Cooperativa Biofruta}

De acordo com os dados da pesquisa, verificou-se que, acima da metade dos produtores se encontra na faixa etária de 30 a 50 anos, fato que pode ser claramente observado na Tabela 1 .

No que diz respeito ao grau de instrução, a Tabela 1 mostrou que $48 \%$ e $30 \%$ possuem nível médio e curso superior, respectivamente. Esses resultados são importantes para a produção, pois um grau de escolaridade maior facilita a capacidade de o produtor interpretar e adaptar as informações pertinentes às novas tecnologias sobre práticas de cultivos e ainda ajuda na capacidade de se adaptar a novas realidades de mercado.

A experiência dos agricultores foi mensurada pelos anos que cada produtor tem na atividade irrigada. A maioria dos entrevistados (87\%) se dedica à irrigação há mais de seis anos, o que demonstra um bom tempo na prática da agricultura irrigada.

Com relação ao local da residência, 35\% dos produtores residem na unidade produtiva, enquanto o restante $(65 \%)$ habita fora do estabelecimento. Quanto à participação de familiares que trabalham na produção agrícola, a tabela mostra que o predomínio é de adultos, com 94\%, 
Tabela 1. Perfil dos produtores da cooperativa Biofruta

\begin{tabular}{lcc}
\hline \multicolumn{1}{c}{ Perfil dos produtores } & Descrição & $\%$ \\
\hline Idade & de 30 a 50 anos & 57 \\
Grau de escolaridade & nível médio & 48 \\
Experiência com irrigação & mais de 6 anos & 87 \\
Experiência em produção orgânica irrigada & mais de 6 anos & 74 \\
Produtores que residem na propriedade & não & 65 \\
Faixa etária dos membros da família & Adultos (>18 anos) & 75 \\
Familiares que trabalham na propriedade & Adultos (>18 anos) & 94 \\
Assistência técnica & técnico da cooperativa & 100 \\
Frequência da assistência técnica & mensal & 87 \\
Participação em capacitação/treinamento & sim & 78 \\
Grau de satisfação & satisfeito & 48 \\
Produzir acerola orgânica trouxe benefícios & sim & 100 \\
Condição legal da propriedade & proprietário & 96 \\
Área física total da propriedade & 6 a 10 ha & 48 \\
Área física com produção de acerola & 0 a 5 ha & 78 \\
Área física com outras culturas & 1 a 5 ha & 91 \\
Decisão de produção & o proprietário & 87 \\
Tipos de sistema de irrigação & microaspersão & 96 \\
Elaboração de projeto inicial & não & 74 \\
\hline
\end{tabular}

Fonte: Dados da pesquisa (2011).

enquanto que é reduzido o uso de mão de obra infantil, ou seja, crianças menores de 12 anos e também de jovens nas atividades da propriedade.

Os resultados mostraram que todos os produtores receberam assistência do próprio técnico da cooperativa. Quando indagados sobre a frequência, $87 \%$ foram visitados mensalmente e $13 \%$ apenas bimestralmente. $\mathrm{O}$ fato de todos receberem assistência do técnico da cooperativa reforça o bom desempenho alcançado por alguns produtores. Por sua vez, o fato de $13 \%$ dos produtores terem visita por um período mais demorado pode ser a causa do baixo desempenho de alguns produtores.

Quanto à capacitação e/ou treinamento dos produtores para a prática de irrigação em acerola, $78 \%$ dos entrevistados informaram haver recebido algum tipo de capacitação e/ou treinamento, enquanto $22 \%$ relataram não haver participado de nenhuma atividade deste tipo. Este resultado pode ser a causa do baixo desempenho técnico-econômico de alguns produtores. Pode-se verificar que quase a metade dos produtores (48\%) está satisfeita com a assistência prestada pela cooperativa.
No concernente à condição legal da propriedade, $96 \%$ são proprietários. Esta situação é muito importante pois, como a maioria é de proprietários, eles podem investir em infraestrutura para alavancar a produção no estabelecimento e ter maior facilidade de acesso ao crédito.

No que se refere ao tamanho da propriedade, $74 \%$ dos produtores entrevistados possuem estabelecimentos/parcelas com áreas pequenas, de zero a dez hectares. No que se refere à área utilizada somente para a produção de acerola, $78 \%$ dos produtores utilizam de zero a cinco hectares e $22 \%$, de seis a dez hectares. Por sua vez, $91 \%$ dos produtores utilizam de zero a cinco hectares para a produção de outras culturas. O fato de a maioria dos produtores (74\%) não obedecer a um plano de exploração confirma a falta de planejamento das atividades, que é um dos graves problemas a entravar o desenvolvimento da agricultura nordestina, mesmo no caso de produção de orgânicos. Pela tabela, observa-se que predomina a irrigação por microaspersão (96\%). 
018 - Rentabilidade da Produção de Acerola Orgânica Sob Condição Determinística e de Risco: estudo do distrito de irrigação Tabuleiro Litorâneo do Piaú́

\subsection{Avaliação econômica da produção de acerola da Cooperativa Biofruta sob condição determinística}

\subsubsection{Determinação da renda bruta e dos custos de produção}

Observa-se, por meio da Tabela 2, que cada produtor, em média, produz 24 toneladas de acerolas verdes e maduras e denota renda bruta média anual de $\mathrm{R} \$ 35.609,49$. O preço da acerola verde é mais alto, sendo $R \$ 1,60 / \mathrm{kg}$, decorrente do fato de a empresa que compra as acerolas da cooperativa ter interesse somente nesse tipo, pois elas são as melhores para a extração da vitamina
C, insumo principal para confecção do seu produto (cápsula de vitamina $\mathrm{C}$ em pó). Já as acerolas maduras, vendidas para cidades vizinhas, somente para a extração e venda da polpa, têm um preço mais baixo, valendo somente $R \$ 1,00 / \mathrm{kg}$.

A Tabela 3 discrimina a composição dos custos de produção. Inicia-se pelo custo operacional efetivo, que guarda relação ao custo variável. Estes custos são representados pelos dispêndios de mão de obra temporária para seleção e colheita, energia elétrica, transporte, taxa da cooperativa, combustíveis e lubrificantes, insumos, gastos de preparo do solo e com plantio e adubação. Observa-se que seu valor totalizou, em média, $\mathrm{R} \$ 21.158,38$, o que representa $62,54 \%$ do custo total anual.

Tabela 2. Quantidade, preço, valor e percentual da renda bruta anual dos produtores da Biofruta, no Perímetro Irrigado Tabuleiros Litorâneos do Piauí

\begin{tabular}{|c|c|c|c|c|}
\hline \multirow{2}{*}{ Produção } & \multicolumn{3}{|c|}{ Média } & \multirow{2}{*}{$\%$} \\
\hline & Quantidade $(\mathrm{Kg})$ & Preço $(K g)$ & Valor $(R \$)$ & \\
\hline Acerolas Verdes & 19.093 & 1,60 & $30.548,68$ & 85,8 \\
\hline Acerolas Maduras & 5.061 & 1,00 & $5.061,00$ & 14,2 \\
\hline Total & 24.154 & - & $35.609,68$ & 100,0 \\
\hline
\end{tabular}

Fonte: Dados da pesquisa (2011).

Tabela 3. Valor total anual, médios e percentuais dos custos operacionais efetivos (COE), custos operacionais totais (COT) e custo total (CT) dos produtores da Biofruta, no Perímetro Irrigado Tabuleiros Litorâneos do Piauí

\begin{tabular}{|c|c|c|c|}
\hline Discriminação & Total (R\$) & Média (R\$) & $\%$ \\
\hline 1. Custos Operacionais Efetivos (COE) & $48.6642,69$ & $21.158,38$ & 62,54 \\
\hline Energia elétrica & $68.786,00$ & $2.980,70$ & 8,81 \\
\hline Transporte & $55.179,68$ & $2.399,12$ & 7,09 \\
\hline Combustíveis e lubrificantes & $25.573,00$ & $1.111,87$ & 3,29 \\
\hline Insumos & $106.827,00$ & $4.644,65$ & 13,73 \\
\hline Taxa Cooperativa & $32.528,02$ & $1.424,26$ & 4,21 \\
\hline Preparo do solo & $29.495,00$ & $1.282,39$ & 3,79 \\
\hline Plantio e Adubação & $22.622,00$ & 983,57 & 2,91 \\
\hline Colheita manual & $127.435,99$ & $5.540,70$ & 16,38 \\
\hline Seleção das frutas & $18.196,00$ & 791,13 & 2,34 \\
\hline 2. Outros Custos Operacionais (OCO) & $254.208,06$ & $11.052,52$ & 32,67 \\
\hline Taxa K2 & $47.529,96$ & $2.066,52$ & 6,11 \\
\hline Mão de obra permanente* & $84.080,00$ & $3.655,65$ & 10,80 \\
\hline Depreciação de maquinas e equipamentos & $43.299,64$ & $1.882,59$ & 5,56 \\
\hline Depreciação de benfeitorias & $11.953,45$ & 519,72 & 1,54 \\
\hline Manutenção & $6.7345,00$ & $2.928,04$ & 8,65 \\
\hline 3. Custo Operacional Total (COT) $(1+2)$ & $740.850,75$ & $32.210,90$ & 95,21 \\
\hline 4. Outros Custos Fixos (OCF) & $37.311,219$ & $1.622,23$ & 4,79 \\
\hline Remuneração Atribuída ao Capital (RAC) & $21.687,219$ & 942,92 & 2,79 \\
\hline Remuneração Atribuída a Terra (RAT) & $15.624,00$ & 679,30 & 2,01 \\
\hline 5. Custo Total (CT) $(3+4)$ & $778.161,97$ & $33.833,13$ & 100,00 \\
\hline
\end{tabular}

* Assemelha-se ao que Martin et al. (1998), denominam de encargos diretos.

Fonte: Dados da pesquisa (2011). 
Somando-se os custos operacionais totais anuais (COT) aos outros custos fixos (OCF) encontra-se o custo total (CT). O custo total médio anual para a produção de acerola orgânica na cooperativa foi de $\mathrm{R} \$ 33.833,13$, considerado um valor muito alto e alvo de debates em reuniões entre os cooperados.

\subsubsection{Análise dos indicadores de rentabilidade}

De acordo com o Quadro 1, fez-se a análise de rentabilidade em três cenários, em que o primeiro é composto por todos os produtores entrevistados pertencentes à cooperativa; e o segundo e terceiro cenários compreendem os produtores que tiveram Margem Líquida negativa $(M L<0)$ e positiva (ML $>0)$, respectivamente.
Quadro 1. Cenários analisados sob condições de riscos dos produtores da cooperativa Biofruta

\begin{tabular}{|c|c|c|}
\hline Cenários & Abrangência & $\begin{array}{c}\text { Produtores } \\
\text { (unid) }\end{array}$ \\
\hline $1^{\underline{o}}$ & Todos os produtores & 23 \\
\hline $2^{\underline{o}}$ & Produtores com $\mathrm{ML}<0$ & 10 \\
\hline $3^{\underline{o}}$ & Produtores com $\mathrm{ML}>0$ & 13 \\
\hline
\end{tabular}

Fonte: Elaboração própria (2011).

Considerando a análise do $1^{\mathrm{o}}$ cenário, que envolve todos os produtores, na Tabela 4, a margem bruta indica o que sobra de dinheiro, no curto prazo, para remunerar os custos fixos. A margem bruta positiva significa que a exploração se remunera e permite ao produtor continuar na atividade em curto prazo. margem bruta negativa significa que atividade é antieconômica naquele período. Dos 23 produtores analisados, sete tiveram margem bruta negativa e 16, margem bruta positiva.

Tabela 4. Indicadores econômicos da produção de acerola da Cooperativa Biofruta para a totalidade da amostra (Cenário 1)

\begin{tabular}{|c|c|c|c|c|c|c|c|c|c|c|}
\hline Produtores & MB & ML & Lucro & TRC & PER & PERam & PERav & PEP & PEPav & PEPam \\
\hline 1 & 8885,8 & 3630,0 & 1457,0 & 2,9 & 19390,0 & 4275,5 & 15142,4 & 1,4 & 1,4 & 1,4 \\
\hline 2 & 6449,4 & 1828,1 & 985,0 & 2,9 & 16883,7 & 3722,9 & 13185,1 & 1,5 & 1,5 & 1,5 \\
\hline 3 & 27195,9 & 22039,4 & 21698,8 & 2,9 & 21469,8 & 4734,1 & 16766,6 & 0,8 & 1,0 & 0,4 \\
\hline 4 & 3189,1 & $-3271,2$ & $-4819,9$ & 2,8 & 16919,2 & 3730,7 & 13212,8 & 1,8 & 1,9 & 1,7 \\
\hline 5 & 17325,2 & 5880,3 & 1879,2 & 2,9 & 24268,9 & 5351,3 & 18952,5 & 1,4 & 1,6 & 0,8 \\
\hline 6 & $-4843,4$ & $-10221,3$ & $-11157,0$ & 2,9 & 14765,4 & 3255,8 & 11530,8 & 2,9 & 3,1 & 2,2 \\
\hline 7 & 6897,2 & 3158,8 & 2413,7 & 2,8 & 17416,7 & 3840,4 & 13601,4 & 1,4 & 1,4 & 1,0 \\
\hline 8 & 22339,0 & 18131,9 & 16433,2 & 2,8 & 21393,3 & 4717,2 & 16706,8 & 1,0 & 1,1 & 0,7 \\
\hline 9 & $-11151,8$ & $-16816,2$ & $-21067,1$ & 2,9 & 12874,3 & 2838,8 & 10054,0 & 16,3 & 17,3 & 12,2 \\
\hline 10 & 29452,8 & 20128,7 & 16514,2 & 2,9 & 21246,6 & 4684,9 & 16592,3 & 1,0 & 1,1 & 0,8 \\
\hline 11 & $-30911,7$ & $-39274,1$ & $-41462,4$ & 2,9 & 38964,6 & 8591,7 & 30428,9 & 4,9 & 5,2 & 3,7 \\
\hline 12 & 69290,6 & 64691,2 & 63819,0 & 2,8 & 36536,6 & 8056,3 & 28532,8 & 0,7 & 0,7 & 0,5 \\
\hline 13 & 4002,0 & 383,5 & $-535,8$ & 2,8 & 19022,6 & 4194,5 & 14855,4 & 1,5 & 1,6 & 1,2 \\
\hline 14 & 195,8 & $-1107,0$ & $-1623,5$ & 2,9 & 12793,8 & 2821,0 & 9991,2 & 1,6 & 1,7 & 1,2 \\
\hline 15 & $-1647,4$ & $-8668,0$ & $-11882,0$ & 2,9 & 17677,2 & 3897,8 & 13804,8 & 2,5 & 2,7 & 1,7 \\
\hline 16 & 1166,9 & $-6278,6$ & $-7806,3$ & 2,8 & 19373,2 & 4271,8 & 15129,3 & 2,0 & 2,1 & 1,5 \\
\hline 17 & $-3560,1$ & $-7260,9$ & $-8094,6$ & 2,9 & 11376,4 & 2508,5 & 8884,2 & 2,7 & 2,9 & 2,1 \\
\hline 18 & $-18295,4$ & $-20893,8$ & $-22051,3$ & 2,9 & 28948,2 & 6383,1 & 22606,7 & 3,0 & 3,2 & 2,3 \\
\hline 19 & $-26623,8$ & $-31448,6$ & $-34321,4$ & 2,9 & 40701,4 & 8974,7 & 31785,2 & 3,3 & 3,3 & 3,3 \\
\hline 20 & 30435,9 & 21395,0 & 19980,3 & 2,9 & 26818,5 & 5913,5 & 20943,6 & 1,0 & 1,0 & 0,8 \\
\hline 21 & 37592,9 & 34413,6 & 33890,4 & 2,8 & 24412,5 & 5383,0 & 19064,6 & 0,8 & 0,8 & 0,6 \\
\hline 22 & 23365,9 & 19564,1 & 18733,9 & 2,9 & 22130,5 & 4879,8 & 17282,6 & 0,9 & 1,0 & 0,7 \\
\hline 23 & 10244,9 & 8392,8 & 8103,0 & 3,9 & 18440,3 & 4066,1 & 14400,7 & 1,1 & 1,3 & 0,5 \\
\hline Total Médio & 8738,9 & 3408,6 & 1786,4 & 2,9 & 21905,4 & 4830,1 & 17106,7 & 2,4 & 2,6 & 1,9 \\
\hline
\end{tabular}

Legenda: MB = Margem Bruta; ML = Margem Líquida; RL = Receita Líquida; TRC = Taxa de Remuneração do Capital; PER = Ponto de Equilíbrio de Rendimento; PERav = Ponto de Equilíbrio de Rendimento da Acerola Verde; PERam = Ponto de Equilíbrio de Rendimento da Acerola Madura; PEP = Ponto de Equilíbrio de Preço; PEPav = Ponto de Equilíbrio de Preço da Acerola Verde; PEPam = Ponto de Equilíbrio de Preço da Acerola Madura.

Fonte: Dados da pesquisa (2011). 
Nota-se que a média da margem bruta, em valores absolutos, foi de $\mathrm{R} \$ 8.738,94$, significando que a média da renda bruta é bem superior à média dos custos operacionais efetivos. Apesar de a margem bruta média ser positiva, observa-se que vários produtores não conseguiram remunerar os seus custos operacionais efetivos, sugerindo uma situação financeira desfavorável para permanecer na atividade mesmo em curto prazo.

A margem líquida mede a lucratividade da atividade em curto prazo, mostrando as condições financeiras e operacionais da atividade agrícola. Essa margem indica a sobra de caixa para cobrir os demais custos fixos e o risco, não computados nesta análise. Dos 23 produtores analisados, dez tiveram margem líquida negativa, enquanto 13 tiveram margem líquida positiva.

O Ponto de Equilíbrio de Rendimento (PER) mede a quantidade mínima de acerola que o produtor deve produzir para cobrir o custo operacional total (COT) de produção de acerolas verdes e maduras, utilizando o preço médio para os dois tipos de acerolas.

Na Tabela 4, pode-se observar que os produtores 4 e 11 exibiram PER de 16.919,21 kg e 38.964,61 $\mathrm{kg}$, enquanto as quantidades efetivamente produzidas foram de $14.400,00 \mathrm{~kg}$ e $12.164,80 \mathrm{~kg}$, respectivamente. Logo, para esses dois produtores, a produção obtida não foi suficiente para cobrir todos os custos de produção, havendo necessidade de melhorar a produtividade. Por sua vez, alguns produtores registraram produção superior ao PER, significando que conseguiram pagar todos os custos de produção, pois eles produziram uma quantidade maior do que a mínima obtida no PER.

O Ponto de Equilíbrio de Preço (PEP), ou Custo Médio, mede o preço mínimo pelo qual o produtor deve vender seu produto para que ele consiga cobrir os custos de produção. Assim, o valor médio da PEPav foi de $\mathrm{R} \$ 2,57$, ou seja, esse é o menor valor pelo qual cada produtor deve vender acerola verde para poder cobrir todos os custos de produção, considerando-se os valores médios de todos os produtores da análise. Por sua vez, o PEPam foi de R \$1,85, ou seja, esse é o menor preço pelo qual cada produtor deve vender a acerola madura.

Na Tabela 5, estão os resultados do $2^{\mathrm{o}}$ Cenário. Verifica-se que todos os produtores são detentores de margem líquida negativa (dez produtores) e que, em média, têm prejuízo anual de $\mathrm{R} \$$ $16.428,56$, fato que merece atenção por parte da cooperativa, pois, se não forem tomadas as providências necessárias, esses produtores poderão deixar o negócio.

Tabela 5. Indicadores econômicos da produção de acerola da cooperativa Biofruta para os produtores com ML negativa (Cenário 2)

\begin{tabular}{cccccccccc}
\hline Produtores & MB & ML & RL & TRC & PER & PERav & PERam & PEPav & PEPam \\
\hline 1 & $3.189,10$ & $-3.271,23$ & $-4.819,86$ & 2,83 & $16.919,21$ & $13.212,84$ & $3.730,69$ & 1,87 & 1,65 \\
2 & $-4.843,36$ & $-10.221,31$ & $-11.157,01$ & 2,87 & $14.765,39$ & $11.530,85$ & $3.255,77$ & 3,10 & 2,19 \\
3 & $-11.151,81$ & $-16.816,23$ & $-21.067,07$ & 2,86 & $12.874,31$ & $10.054,03$ & $2.838,78$ & 17,28 & 12,20 \\
4 & $-30.911,74$ & $-39.274,07$ & $-41.462,42$ & 2,85 & $38.964,61$ & $30.428,92$ & $8.591,70$ & 5,19 & 3,67 \\
5 & 195,76 & $-1.106,96$ & $-1.623,54$ & 2,86 & $12.793,85$ & $13.804,75$ & $3.897,81$ & 2,61 & 1,75 \\
6 & $-1.647,36$ & $-8.668,01$ & $-11.882,03$ & 2,90 & $17.677,15$ & $15.129,28$ & $4.271,80$ & 2,77 & 1,75 \\
7 & $1.166,90$ & $-6.278,64$ & $-7.806,34$ & 2,83 & $19.373,22$ & $8.884,22$ & $2.508,49$ & 1,24 & 0,88 \\
8 & $-3.560,07$ & $-7.260,86$ & $-8.094,60$ & 2,85 & $11.376,35$ & $22.606,71$ & $6.383,07$ & 7,26 & 5,13 \\
9 & $-18.295,40$ & $-20.893,80$ & $-22.051,29$ & 2,86 & $28.948,16$ & $31.785,24$ & $8.974,66$ & 4,55 & 3,24 \\
10 & $-26.623,83$ & $-31.448,58$ & $-34.321,42$ & 2,86 & $40.701,39$ & $20.943,58$ & $5.913,48$ & 2,17 & 2,17 \\
Total Médio & $\mathbf{- 9 . 2 4 8 , 1 8}$ & $\mathbf{- 1 4 . 5 2 3 , 9 7}$ & $\mathbf{- 1 6 . 4 2 8 , 5 6}$ & $\mathbf{2 , 8 6}$ & $\mathbf{2 1 . 4 3 9 , 3 6}$ & $\mathbf{1 7 . 8 3 8 , 0 4}$ & $\mathbf{5 . 0 3 6 , 6 2}$ & $\mathbf{4 , 8 1}$ & $\mathbf{3 , 4 6}$ \\
\hline
\end{tabular}

Legenda: $\mathrm{MB}=$ Margem Bruta; $\mathrm{ML}=$ Margem Líquida; $\mathrm{RL}=$ Receita Líquida; TRC= Taxa de Remuneração do Capital; PER=Ponto de Equilíbrio de Rendimento; PERav = Ponto de Equilíbrio de Rendimento da Acerola Verde; PERam= Ponto de Equilíbrio de Rendimento da Acerola Madura; PEPav = Ponto de Equilíbrio de Preço da Acerola Verde; PEPam = Ponto de Equilíbrio de Preço da Acerola Madura.

Fonte: Dados da pesquisa (2011). 
Os produtores desse cenário têm que produzir, no mínimo, em média, 17.838,04 kg de acerolas verdes e $5.037 \mathrm{~kg}$ de acerolas maduras para conseguirem pelo menos pagar seus custos e não ficarem no prejuízo. É o que se mostra por meio dos indicadores PERav e PERam, respectivamente. Isso comprova o prejuízo identificado, pois esses produtores só estão produzindo, em média, $9.269 \mathrm{~kg}$ de acerolas verdes e $2.174 \mathrm{~kg}$ de acerolas maduras, valores esses muito abaixo dos mínimos esperados.

A Tabela 6 é composta somente pelos produtores que expressam margem líquida positiva $(\mathrm{ML}>0)$. Dos 23 produtores analisados, somente 13 fazem parte deste cenário (3ํㅡㄹório).

Em média, esses produtores estão obtendo receita líquida anual positiva de $\mathrm{R} \$ 15.797,84$, considerada boa para os padrões da agricultura nordestina, pois o produtor chega a ter uma remuneração mensal de R\$1.316,49, levando em consideração que esse valor representa a remuneração do produtor pelo seu trabalho executivo e administrativo.

Por meio do cálculo do PERav e PERam, constata-se que esses produtores devem produzir, no mínimo e em média $16.544 \mathrm{~kg}$ de acerolas verdes e $4.671 \mathrm{~kg}$ de acerolas maduras para cobertura de seus custos. Estes resultados comprovam o fato de eles estarem com receita líquida positiva, já que produziram, em média, $26.656 \mathrm{~kg}$ de acerolas verdes e $7.280 \mathrm{~kg}$ de acerolas maduras.

Por meio da análise do PEPav e do PEPam, mostra-se até quanto os preços da acerola verde e madura poderiam ser reduzidos sem afetar a viabilidade econômica do negócio. Constata-se que, mesmo se o preço da acerola verde fosse de $\mathrm{R} \$ 1,16$ e o da madura de $\mathrm{R} \$ 0,80$, os produtores não teriam receita líquida positiva, tampouco prejuízo, pois são os valores encontrados para os pontos de equilíbrio de preços.

\subsection{Análise de rentabilidade da produção de acerola da Cooperativa Biofruta sob condição de risco}

\subsubsection{Análise de sensibilidade}

Antes de efetuar a análise de risco, acreditou-se ser importante submeter os resultados do estudo à técnica de análise de sensibilidade, para determinar quais variáveis se mostram mais sensíveis, ou seja, que têm maior influência sobre a certeza dos resultados.

Tabela 6. Indicadores econômicos da produção de acerola da cooperativa Biofruta para os produtores com ML positiva (Cenário 3)

\begin{tabular}{cccccccccc}
\hline Produtores & MB & ML & RL & TRC & PER & PERav & PERam & PEPav & PEPam \\
\hline 1 & 8885,80 & 3630,00 & 1456,98 & 2,87 & 19390,02 & 15142,40 & 4275,50 & 1,45 & 1,38 \\
2 & 6449,41 & 1828,06 & 985,00 & 2,87 & 16883,67 & 13185,09 & 3722,85 & 1,45 & 1,45 \\
3 & 27195,90 & 22039,35 & 21698,79 & 2,86 & 21469,83 & 16766,60 & 4734,10 & 1,04 & 0,40 \\
4 & 17325,20 & 5880,29 & 1879,23 & 2,88 & 24268,89 & 18952,49 & 5351,29 & 1,60 & 0,77 \\
5 & 6897,18 & 3158,78 & 2413,67 & 2,85 & 17416,70 & 13601,36 & 3840,38 & 1,44 & 1,02 \\
6 & 22339,00 & 18131,90 & 16433,21 & 2,85 & 21393,27 & 16706,80 & 4717,22 & 1,05 & 0,74 \\
7 & 29452,78 & 20128,65 & 16514,16 & 2,86 & 21246,62 & 16592,28 & 4684,88 & 1,07 & 0,75 \\
8 & 69290,60 & 64691,20 & 63819,04 & 2,84 & 36536,60 & 28532,80 & 8056,32 & 0,72 & 0,51 \\
9 & 4001,97 & 383,49 & $-535,82$ & 2,84 & 19022,57 & 14855,44 & 4194,48 & 1,59 & 1,20 \\
10 & 30435,94 & 21394,97 & 19980,32 & 2,87 & 26818,51 & 9991,20 & 2821,04 & 0,50 & 0,38 \\
11 & 37592,90 & 34413,62 & 33890,36 & 2,84 & 24412,50 & 19064,64 & 5382,96 & 0,81 & 0,57 \\
12 & 23365,86 & 19564,11 & 18733,92 & 2,89 & 22130,54 & 17282,57 & 4879,78 & 1,01 & 0,71 \\
13 & 10244,90 & 8392,80 & 8103,03 & 3,85 & 18440,27 & 14400,70 & 4066,08 & 1,33 & 0,55 \\
Total Médio & $\mathbf{2 2 5 7 5 , 1 9}$ & $\mathbf{1 7 2 0 2 , 8 6}$ & $\mathbf{1 5 7 9 7 , 8 4}$ & $\mathbf{2 , 9 4}$ & $\mathbf{2 2 2 6 3 , 8 5}$ & $\mathbf{1 6 5 4 4 , 1 8}$ & $\mathbf{4 6 7 1 , 3 0}$ & $\mathbf{1 , 1 6}$ & $\mathbf{0 , 8 0}$ \\
\hline
\end{tabular}

Legenda: $\mathrm{MB}=$ Margem Bruta; $\mathrm{ML}=$ Margem Líquida; $\mathrm{RL}=$ Receita Líquida; TRC $=$ Taxa de Remuneração do Capital; PER $=$ Ponto de Equilíbrio de Rendimento; PERav = Ponto de Equilíbrio de Rendimento da Acerola Verde; PERam = Ponto de Equilíbrio de Rendimento da Acerola Madura; PEPav = Ponto de Equilíbrio de Preço da Acerola Verde; PEPam = Ponto de Equilíbrio de Preço da Acerola Madura.

Fonte: Dados da pesquisa (2011). 
022 - Rentabilidade da Produção de Acerola Orgânica Sob Condição Determinística e de Risco: estudo do distrito de irrigação Tabuleiro Litorâneo do Piauí

Foram selecionadas como variáveis críticas aquelas que variaram em até $-0,62 \%$. Logo, as variáveis iniciais analisadas, que eram no total de 18, foram reduzidas para 13 depois de aplicar o critério de corte. As variáveis selecionadas são as que estão em negrito na Tabela 7 e serão tomadas como aleatórias para a análise de risco, sendo as demais assumidas como constantes.

\subsubsection{Identificação das distribuições de probabilidade}

A análise de rentabilidade em condições de risco foi feita seguindo o método de Monte Carlo por meio do programa computacional "Aleaxprj". De acordo com a amostra e utilizando o método de identificação de distribuição de probabilidade mais adequada para as variáveis, optou-se pela distribuição triangular, que exige valores mínimo, máximo e médio.

\subsubsection{Simulação dos valores aleatórios}

A receita bruta é a variável aleatória de maior importância na determinação das distribuições de probabilidades dos indicadores de rentabilidade.

Podem ser verificadas na Tabela 8 as distribuições de probabilidade das variáveis que determinam a Receita Bruta (RB) dos produtores pesquisados. Para facilitar a análise de risco, considerou-se uma área média comum de exploração de um hectare de acerola orgânica. Como a área é tomada como constante, logo foi considerada na análise de risco uma distribuição do tipo "Spike".

Para a produtividade e para os preços, ante os dados coletados e a análise dos especialistas, foram identificados os valores mínimo, máximo e médio.

$\mathrm{Na}$ identificação dos custos e das receitas também foram levados em conta os três cenários para o cálculo do valor da margem líquida obtida pelos produtores.

Tabela 7. Sensibilidade das variáveis, variação na receita líquida e porcentagens

\begin{tabular}{|c|c|c|}
\hline Descrição dos Custos & Variação na Receita Líquida (R\$) & $\%$ \\
\hline Preço da acerola verde & 305,49 & 17,10 \\
\hline Produtividade média acerola verde & 305,49 & 17,10 \\
\hline Preço acerola madura & 50,61 & 2,83 \\
\hline Produtividade média acerola madura & 50,61 & 2,83 \\
\hline Colheita manual & $-55,41$ & $-3,10$ \\
\hline Insumos & $-46,45$ & $-2,60$ \\
\hline Funcionários & $-36,56$ & $-2,05$ \\
\hline Energia elétrica & $-29,81$ & $-1,67$ \\
\hline Manutenção & $-29,28$ & $-1,64$ \\
\hline Transporte & $-23,99$ & $-1,34$ \\
\hline Taxa K2 & $-20,67$ & $-1,16$ \\
\hline Depreciação de maquinas e equipamentos & $-18,83$ & $-1,05$ \\
\hline Taxa Cooperativa & $-14,14$ & $-0,79$ \\
\hline Preparo do solo & $-12,82$ & $-0,72$ \\
\hline Combustíveis e lubrificantes & $-11,12$ & $-0,62$ \\
\hline Plantio e Adubação & $-9,84$ & $-0,55$ \\
\hline Remuneração Atribuída ao Capital (RAC) & $-9,43$ & $-0,53$ \\
\hline Seleção das frutas & $-7,91$ & $-0,44$ \\
\hline Remuneração Atribuída a Terra (RAT) & $-6,79$ & $-0,38$ \\
\hline Depreciação de benfeitorias & $-5,20$ & $-0,29$ \\
\hline
\end{tabular}

Fonte: Dados da pesquisa (2011) 
Tabela 8. Identificação, definição e distribuição de probabilidade nos três cenários das variáveis que determinam a renda bruta dos produtores de acerola da cooperativa Biofruta

\begin{tabular}{|c|c|c|c|}
\hline \multicolumn{4}{|c|}{ Cenário 1 (Todos os produtores) } \\
\hline Variável & Definição da variável & Distribuição & Valores \\
\hline PAV & Preço Acerola Verde & Triangular & {$[1,60 ; 1,52 ; 1,68]$} \\
\hline PAM & Preço Acerola Madura & Triangular & {$[1,00 ; 0,76 ; 1,17]$} \\
\hline AAC & Área da acerola & Spike & {$[1]$} \\
\hline PRAV & Produtividade da Acerola Verde & Triangular & {$[17.809,00 ; 7.953,00 ; 45.061,00]$} \\
\hline PRAM & Produtividade da Acerola Madura & Triangular & {$[4.767,00 ; 2.033,00 ; 12.500,00]$} \\
\hline \multicolumn{4}{|c|}{ Cenário $2(\mathrm{ML}<0)$} \\
\hline Variável & Definição da variável & Distribuição & Valores \\
\hline PAV & Preço Acerola Verde & Triangular & {$[1,60 ; 1,52 ; 1,68]$} \\
\hline PAM & Preço Acerola Madura & Triangular & {$[1,00 ; 0,76 ; 1,17]$} \\
\hline $\mathrm{AAC}$ & Área da acerola & Spike & {$[1]$} \\
\hline PRAV & Produtividade da Acerola Verde & Triangular & {$[9.248,33 ; 6.234,91 ; 13.325,63]$} \\
\hline PRAM & Produtividade da Acerola Madura & Triangular & {$[2.147,10 ; 1.563,73 ; 2.906,48]$} \\
\hline \multicolumn{4}{|c|}{ Cenário 3 (ML > 0) } \\
\hline Variável & Definição da variável & Distribuição & Valores \\
\hline PAV & Preço Acerola Verde & Triangular & {$[1,60 ; 1,52 ; 1,68]$} \\
\hline PAM & Preço Acerola Madura & Triangular & {$[1,00 ; 0,76 ; 1,17]$} \\
\hline $\mathrm{AAC}$ & Área da acerola & Spike & {$[1]$} \\
\hline PRAV & Produtividade da Acerola Verde & Triangular & {$[26.574,03 ; 16.089,33 ; 45.060,61]$} \\
\hline PRAM & Produtividade da Acerola Madura & Triangular & {$[7.280,98 ; 4.033,41 ; 12.500,00]$} \\
\hline
\end{tabular}

Fonte: Dados da pesquisa (2011).

Os custos operacionais efetivos e os custos totais foram considerados separadamente. As variáveis Custos Operacionais Efetivos (COE), Custos Operacionais Totais (COT) e Custos Totais (CT) foram havidas como aleatórias, sendo expressas por distribuições triangulares, enquanto que, para as variáveis que na análise de sensibilidade não foram consideradas críticas, foram admitidas distribuições do tipo "Spike" ou constante. São elas: plantio e adubação; seleção das frutas; depreciação de benfeitorias e remuneração atribuída ao capital e à terra.

\subsubsection{Cálculo dos Indicadores}

O processo de produção de acerola orgânica enseja dois produtos comercializáveis - a acerola verde e a madura - que proporcionam preços e produtividades diferentes. A acerola verde tem tanto o preço mais alto como a produtividade maior do que a acerola madura. Logo, a receita bruta será também diferente para cada tipo de acerola analisada.

Assim, conceitualmente, a receita bruta (RB) de cada cenário foi assim definida:
Receita Bruta da Acerola Verde:

$$
R B A V=P A V \times A A C \times P R A V
$$

em que:

$R B A V=$ Receita Bruta da Acerola Verde;

$P A V=$ Preço da Acerola Verde;

$A A C$ = Área da Acerola Verde;

$P R A V=$ Produtividade da Acerola Verde.

Receita Bruta da Acerola Madura:

$$
R B A M=P A M \times A A C \times P R A M
$$

em que:

$R B A M=$ Receita Bruta da Acerola Madura;

$P A V=$ Preço da Acerola Madura;

$A A C$ = Área da Acerola Madura;

$P R A V=$ Produtividade da Acerola Madura.

Logo, a Receita Bruta Total é:

$$
R B=R B A V+R B A M
$$

Para qualquer um dos cenários especificados, as variáveis aleatórias Custo Operacional Efetivo (COE), Custo Operacional Total (COT) e Custo 
024 - Rentabilidade da Produção de Acerola Orgânica Sob Condição Determinística e de Risco: estudo do distrito de irrigação Tabuleiro Litorâneo do Piauí

Total (CT) foram funcionalmente definidas no programa como:

- $\mathrm{COE}=$ somatório dos gastos com mão de obra permanente, energia, tarifa de conta de água, combustíveis e lubrificantes, insumos, taxa de cooperativa, preparo do solo, plantio e adubação, colheita manual, seleção, transporte e manutenção;

- $\mathrm{COT}=$ somatório do COE com a depreciação de máquinas, equipamentos e benfeitorias;

- $\mathrm{CT}$ = somatório do COT com a remuneração atribuída ao capital e à terra.

\subsubsection{Distribuição cumulativa de probabilidade dos indicadores}

\section{Cenário 1 (Todos os produtores)}

Nas 1.000 simulações efetuadas, alguns indicadores apontaram riscos elevados, enquanto para outros o risco é baixo. Na Tabela 9, a margem bruta, por exemplo, apontou $51,6 \%$ de possibilidade de ser maior do que zero e valor médio de $R \$ 1.530,56$ por hectare. Quando se estabelece o limite de $\mathrm{R} \$ 5.330,00$, que representa o valor médio dos custos fixos, a probabilidade de pagamento é de $44,7 \%$ e a média é de $\mathrm{R} \$ 4.728,74 /$ hectare, ou seja, significa que o produtor tem apenas $44,7 \%$ de chance de a margem bruta cobrir os custos fixos. Obteve-se também uma probabilidade de $40,7 \%$ de a margem bruta ser maior do que R\$ $8.738,94$, que representa a margem bruta média dos produtores na análise determinística.

\section{Cenário $2(\mathrm{ML}<0)$}

Na Tabela 10, encontra-se a análise dos indicadores de rentabilidade para os produtores com margem líquida negativa, ou seja, para aqueles produtores que não detêm renda bruta suficiente para pagar seus custos fixos. Logo, as probabilidades de ocorrerem margem bruta, margem líquida e receita líquida maiores do que zero são de $0 \%$, ou seja, para esses produtores, não existem possibilidades de viabilizar o negócio. Eles também não estão remunerando o seu capital pois, como pode ser constatado, a possibilidade de a TRC ser maior do que $6 \%$ é de $0 \%$.

Tabela 9. Cenário 1 (Todos os produtores): indicadores de rentabilidade de um hectare de acerola orgânica produzida pela cooperativa Biofruta nos Perímetros Irrigados Tabuleiro Litorâneo do Piauí

\begin{tabular}{|c|c|c|c|c|}
\hline Indicador (I) & Média & Desvio padrão & Limite (Li)* & $\mathrm{P}(\mathrm{I}>\mathrm{Li})^{* *}$ \\
\hline \multirow{3}{*}{$\mathrm{MB}$} & $1.530,56$ & $13.345,94$ & 0,00 & 0,5160 \\
\hline & $4.728,74$ & $13.945,84$ & $5.330,00$ & 0,4470 \\
\hline & $5.734,92$ & $14.325,88$ & $8.738,94$ & 0,4070 \\
\hline \multirow{3}{*}{ ML } & $2.372,64$ & $15.079,95$ & 0,00 & 0,5290 \\
\hline & $1.736,76$ & $14.348,65$ & $1.622,65$ & 0,4730 \\
\hline & $2.726,51$ & $14.321,94$ & $3.408,60$ & 0,4700 \\
\hline \multirow{3}{*}{ RL } & 750,42 & $15.079,94$ & 0,00 & 0,5120 \\
\hline & 861,63 & $14.030,08$ & $1.776,36$ & 0,4560 \\
\hline & $-2.046,74$ & $13.798,52$ & $5.450,00$ & 0,3010 \\
\hline \multirow{3}{*}{ TRC } & 5,15 & 45,86 & 0,06 & 0,5240 \\
\hline & 5,49 & 42,67 & 0,10 & 0,5340 \\
\hline & 6,23 & 43,56 & 0,12 & 0,5080 \\
\hline PER & $29.935,62$ & $3.683,13$ & $21.905,00$ & 0,9900 \\
\hline PERAV & $22.829,94$ & $2.808,88$ & $17.106,00$ & 0,9870 \\
\hline PERAM & $6.326,74$ & 778,41 & $4.830,00$ & 0,9800 \\
\hline PEPAV & 1,85 & 0,74 & 2,57 & 0,1700 \\
\hline PEPAM & 1,21 & 0,49 & 1,85 & 0,1020 \\
\hline
\end{tabular}

Legenda: MB = Margem Bruta; ML = Margem Líquida; RL = Receita Líquida; TRC = Taxa de Remuneração do Capital; PER = Ponto de Equilíbrio de Rendimento; PERav = Ponto de Equilíbrio de Rendimento da Acerola Verde; PERam = Ponto de Equilíbrio de Rendimento da Acerola Madura; PEPav $=$ Ponto de Equilíbrio de Preço da Acerola Verde; PEPam = Ponto de Equilíbrio de Preço da Acerola Madura.

* Limite mínimo preestabelecido para o indicador I.

** Probabilidade do valor do indicador ser maior que o limite Li.

Fonte: Pesquisa direta (2011). 
Tabela 10. Cenário 2 (Produtores com ML < 0): indicadores de rentabilidade de um hectare de acerola orgânica produzida pela cooperativa Biofruta nos Perímetros Irrigados Tabuleiro Litorâneo do Piauí

\begin{tabular}{ccccc}
\hline Indicador (I) & Média & Desvio padrão & Limite $(\mathbf{L i})^{*}$ & P(I $\left.^{*} \mathbf{L i}\right)^{* *}$ \\
\hline \multirow{2}{*}{ MB } & $-26.756,46$ & $3.804,46$ & 0,00 & 0 \\
& $-26.912,67$ & $3.704,65$ & $5.275,00$ & 0 \\
\hline \multirow{2}{*}{ ML } & $-29.639,76$ & $3.828,35$ & 0,00 & 0 \\
& $-29.761,49$ & $3.774,93$ & $1.904,00$ & 0 \\
\hline \multirow{2}{*}{ RL } & $-31.544,35$ & $3.828,35$ & 0,00 & 0 \\
& $-31.666,08$ & $3.774,93$ & $5.450,00$ & 0 \\
\hline \multirow{2}{*}{ TRC } & $-75,76$ & 9,54 & 0,06 & 0 \\
& $-75,35$ & 9,23 & 0,10 & 0 \\
\hline PER & $-76,06$ & 9,41 & $21.439,00$ & 1 \\
PERAV & $32.040,34$ & $2.024,78$ & $17.838,00$ & 1 \\
PERAM & $24.541,63$ & $1.552,86$ & $5.036,00$ & 1 \\
\hline PEPAV & $6.615,50$ & 500,50 & 4,81 & 0,3240 \\
PEPAM & 4,52 & 0,77 & 3,46 & 0,4230
\end{tabular}

Legenda: $\mathrm{MB}=$ Margem Bruta; $\mathrm{ML}=$ Margem Líquida; $\mathrm{RL}=$ Receita Líquida; $\mathrm{TRC}=$ Taxa de Remuneração do Capital; PER $=$ Ponto de Equilíbrio de Rendimento; PERav = Ponto de Equilíbrio de Rendimento da Acerola Verde; PERam = Ponto de Equilíbrio de Rendimento da Acerola Madura; PEPav = Ponto de Equilíbrio de Preço da Acerola Verde; PEPam = Ponto de Equilíbrio de Preço da Acerola Madura.

* Limite mínimo preestabelecido para o indicador I.

** Probabilidade do valor do indicador ser maior que o limite Li.

Fonte: Pesquisa direta (2011).

\section{Cenário $3(\mathrm{ML}>0)$}

Ao se analisar a Tabela 11, pode-se verificar que as probabilidades de ocorrerem margem bruta, margem líquida e receita líquida maio- res do que zero são de $96,2 \%, 92,3 \%$ e $89 \%$, respectivamente, ou seja, esses produtores terão a garantia de que a produção de acerola será uma atividade segura com quase $100 \%$ de certeza, portanto, com risco quase zero.

Tabela 11. Cenário 3 (Produtores com ML > 0): indicadores de rentabilidade de um hectare de acerola orgânica produzida pela cooperativa Biofruta nos Perímetros Irrigados Tabuleiro Litorâneo do Piauí

\begin{tabular}{|c|c|c|c|c|}
\hline Indicador (I) & Média & Desvio padrão & Limite $(\mathrm{Li})^{*}$ & $\mathrm{P}(\mathrm{I}>\mathrm{Li})^{* *}$ \\
\hline \multirow{3}{*}{ MB } & $16.916,04$ & $10.322,04$ & 0,00 & 0,9620 \\
\hline & $19.135,01$ & $10.045,00$ & $22.575,00$ & 0,3520 \\
\hline & $18.204,33$ & $10.353,11$ & $5.372,35$ & 0,8990 \\
\hline \multirow{3}{*}{ ML } & $14.377,78$ & $10.365,89$ & 0,00 & 0,9230 \\
\hline & $16.620,31$ & $10.058,65$ & $17.202,00$ & 0,4390 \\
\hline & $15.625,53$ & $10.350,37$ & $1.405,00$ & 0,9280 \\
\hline \multirow{3}{*}{ RL } & $12.972,76$ & $10.365,89$ & 0,00 & 0,8900 \\
\hline & $15.215,29$ & $10.058,65$ & $15.797,00$ & 0,4390 \\
\hline & $14.220,51$ & $10.350,37$ & $5.450,00$ & 0,7830 \\
\hline \multirow{3}{*}{ TRC } & 54,94 & 37,95 & 0,06 & 0,9390 \\
\hline & 50,09 & 37,33 & 0,10 & 0,9080 \\
\hline & 58,58 & 36,83 & 0,12 & 0,9660 \\
\hline PER & $27.543,68$ & $1.722,38$ & $22.263,00$ & 1,0000 \\
\hline PERAV & $21.704,88$ & $1.306,87$ & $16.544,00$ & 1,0000 \\
\hline PERAM & $6.158,35$ & 377,64 & $4.671,00$ & 1,0000 \\
\hline PEPAV & 1,28 & 0,29 & 1,16 & 0,6270 \\
\hline PEPAM & 0,83 & 0,20 & 0,80 & 0,5070 \\
\hline
\end{tabular}

Legenda: $\mathrm{MB}=$ Margem Bruta; $\mathrm{ML}=$ Margem Líquida; $\mathrm{RL}=$ Receita Líquida; $\mathrm{TRC}=$ Taxa de Remuneração do Capital; PER=Ponto de Equilíbrio de Rendimento; PERav = Ponto de Equilíbrio de Rendimento da Acerola Verde; PERam= Ponto de Equilíbrio de Rendimento da Acerola Madura; PEPav $=$ Ponto de Equilíbrio de Preço da Acerola Verde; PEPam = Ponto de Equilíbrio de Preço da Acerola Madura.

* Limite mínimo preestabelecido para o indicador I.

** Probabilidade do valor do indicador ser maior que o limite Li.

Fonte: Pesquisa direta (2011). 
Ao verificar a probabilidade de esses mesmos indicadores serem maiores do que as respectivas médias obtidas na análise determinística, a garantia de sucesso da atividade já diminui consideravelmente. As possibilidades de as margens bruta e líquida e de a receita líquida serem maiores do que suas médias passam a ter percentuais de $35 \%, 43,9 \%$ e $43,9 \%$, respectivamente. Isso acontece porque os valores médios são muito altos.

\section{Conclusões}

Os produtores da cooperativa Biofruta são, na sua maioria, homens de 30 a 50 anos, de boa instrução e com experiência em culturas irrigadas e orgânicas (mais de seis anos). Todos expressam que trabalhar com orgânicos proporcionou melhoria na qualidade de vida, tanto do próprio produtor como de seus funcionários, além, é claro, de trazer benefícios para o consumidor final.

A maioria dos produtores não tem recursos próprios para financiar suas culturas, recorrendo a instituições financeiras, enfrentando dificuldades de aprovação de crédito e repasse de verbas. A assistência técnica se dá mensalmente pelo técnico da própria cooperativa e, em sua maioria, os cooperados se acham satisfeitos com a cooperativa.

No $1^{\mathrm{o}}$ Cenário, considerou-se a amostra total de produtores, em que $56,52 \%$ dos entrevistados denotaram margem líquida positiva. As análises de risco, contudo, apontam probabilidades muito baixas para pagamento de custos fixos e variáveis da atividade. Poucos indicadores apontaram resultados acima dos limites mínimos toleráveis. Portanto, identifica-se a existência de alto risco na atividade.

Já no $2^{\mathrm{o}}$ Cenário, que considera somente os produtores que tiveram margem líquida negativa, o valor médio da receita líquida foi negativo, significando que esses produtores não estão conseguindo sequer pagar seus custos, muito menos ter uma remuneração plausível. As médias anuais dos indicadores mostraram-se sempre abaixo dos limites mínimos preestabelecidos aceitáveis, havendo grande risco de prejuízo.

Ao analisar o 3 o Cenário, ou seja, os produtores que tiveram margem líquida positiva, o valor médio da receita líquida foi positivo. As médias anuais dos indicadores mostraram-se acima dos limites mínimos aceitáveis, havendo risco mínimo de prejuízo. Portanto, conclui-se que esse grupo de produtores pode e deve continuar desenvolvendo a atividade.

Pode-se concluir que a produção de acerola orgânica nos Tabuleiros Litorâneos do Piauí, para o grupo de 13 produtores que utilizam melhor padrão tecnológico (e que exprimem margem líquida positiva), confirma a hipótese de ser rentável e de baixo risco, não acontecendo o mesmo para o grupo de produtores que desenvolve o processo produtivo com baixo nível tecnológico.

$\mathrm{O}$ produtor com margem líquida positiva e que demonstrou melhor padrão tecnológico se caracteriza por ser proprietário do lote, ter mais de seis anos de experiência em agricultura irrigada, receber assistência técnica mensal de técnico da cooperativa, participar periodicamente de capacitação e treinamento sobre manejo de culturas, produzir em uma área de até cinco hectares, utilizar o sistema de irrigação por microaspersão, elaborar projeto para dar início ao seu negócio, enfim, tomar decisões planejadas.

Ante o crescimento do consumo mundial de produtos orgânicos, é fundamental mencionar que o cenário negativo, observado para os dez produtores que registraram margem líquida negativa, tende a se alterar de forma positiva, diminuindo, consequentemente, o risco e elevando a possibilidade de melhoria da rentabilidade da produção de acerola orgânica.

Para tanto, devem ser adotadas políticas públicas que ajudem na redução das dificuldades dos produtores quanto à aquisição de financiamentos, assim como rever os antigos contratos. Periodicamente devem ser oferecidos cursos de capacitação e treinamento em produção de acerola orgânica e em gestão e comercialização agrícola. A assistência técnica deve ser 
individualizada e de qualidade para auxiliar na correta utilização dos insumos.

Sugerem-se também estudos para definir os melhores níveis tecnológicos de produção, visando identificar grupos dinâmicos e viáveis, que servirão de modelo para o desenvolvimento da atividade por futuros produtores.

\section{Referências}

AZEVEDO FILHO, A. J. B. V. ALEAXPRJ - Sistema para simulação e análise econômica de projetos em condições de risco. Piracicaba: Escola Superior de Agricultura Luiz de Queiroz, 1988. 158p.

BUARQUE, C. Avaliação econômica de projetos. Rio de Janeiro: Campus, 1989. 266 p.

CAMPOS, R. T. Efeitos do ataque do bicudo na cotonicultura do semiárido cearense. 1991. 160 f. Tese (Doutorado em Economia) - Universidade Federal de Pernambuco (PIMES), Recife, 1991.

. Tipologia dos produtores de ovinos e caprinos no Estado do Ceará. Revista Econômica do Nordeste, Fortaleza, v. 34, n. 1, jan./mar. 2003.

CERVEIRA, R.; CASTRO, M. C. de. Consumidores de produtos orgânicos da cidade de São Paulo: características de um padrão de consumo. Informações Econômicas, São Paulo, v. 29, n. 12, p. 7-20, 1999.

FISHMAN, G. S. Monte Carlo: concepts, algorithms and applications.USA: Springer, 1995.

HERTZ, O. B. Risk analysis in capital investment. Harvard Business Review, Boston, v. 42, n. 1, p. 95-106, jan./fev. 1964.

HOFFMANN, R. et al. Administração da empresa agrícola. 7. ed. São Paulo: Pioneira, 1992. 523p.

KAY, R. D. Farm management: planning, control and implementation. New York: McGraw-Hill, 1986. 401p.
MARTIN, N. B. et al. Sistema integrado de custos agropecuários - CUSTAGRI. Informações Econômicas, São Paulo, v. 28, n. 1, p. 07-28, jan. 1998.

MOUTINHO, D. A., SANDERS JUNIOR, J. H. e WEBER, M. T. Tomada de decisão sob condições de risco em relação a nova tecnologia para a produção de feijão de corda. Revista de Economia e Sociologia Rural, Brasília, v. 16, n. 4, p. 41-58, 1978.

NORONHA, J. F. Projetos agropecuários: administração financeira, orçamento e viabilidade econômica. 2. ed. São Paulo: Atlas, 1988.

PAREJA, I. V. Decisiones de inversión para la valoración financiera de proyectos y empresas. 6. ed. Buenos Aires: Fondo Editorial Consejo, 2009. 692 p.

PONCIANO, N. J. et al. Análise de viabilidade econômica e de risco da fruticultura na região norte Fluminense. Revista de Economia e Sociologia Rural, Rio de Janeiro, v. 42, n. 04, p. 615-635, out./dez. 2004. Disponível em: <http://www.scielo.br/scielo.php>. Acesso em: 11 abr. 2012.

POULIQUEN, L. Y. Risk analysis in project appraisal. Baltimore: The Johns Hopkins University, 1970.

SANTOS, J. C. dos. Análise da rentabilidade, sob condições de risco, de um sistema agroflorestal adotado por pequenos produtores de cacau na região da Transamazônica, Pará. 1996. 128 f. Dissertação (Mestrado em Economia Rural) - Centro de Ciências Agrárias, Universidade Federal do Ceará, Fortaleza, 1996.

STRINGHETA, P. C. e MUNIZ, J. R. Alimentos orgânicos: produção, tecnologia e certificação. Minas Gerais: UFV, 2003.

STUDART, T. M. C. Análise de incertezas na determinação de vazões regularizadas em climas semiáridos. 2000. Tese (Doutorado em Recursos Hídricos) - Universidade Federal do Ceará, Fortaleza, 2000.

WILLER, H. e YUSSEFI, M. Organic agriculture worldwide. Dürkheim: Stiftunng Ökologie e Landbau; Bad: SÖL, 2001. 133 p. 
